\title{
In vitro shoot multiplication and rooting of wild Paeonia
}

\section{officinalis L., subsp. officinalis}

\author{
G. Marino, F. Grandi, E. Muzzi and M.E. Giorgioni \\ Dip. Scienze e Tecnologie Agro-Alimentari (DISTAL), Università di Bologna, Bologna, Italy
}

\section{Summary}

Paeonia officinalis L., subsp. officinalis, is a herbaceous peony spontaneously growing on rocky slopes, up to $1,800 \mathrm{~m}$ of altitude, from Southern France to Albany, that includes Tuscan and Emilian Apennines. Its propagation occurs by rhizome or seeds under natural growing conditions; however, seeds need a couple of years to germinate. The aim of the present research was to set up a protocol for the in vitro propagation of this species, useful for its reintroduction in the natural environment, and suitable at nursery level. The combined effect of 6-benzyladenine (BA) and polyvinylpyrrolidone (PVP) was investigated on shoot multiplication of single shoots and small shoot clusters, in agarized culture media. A two-step rooting procedure was used, providing one-week culture of shoots in complete darkness on media enriched with indole-3-butyric acid (IBA) and their transfer to auxin-free media. Agarized media or perlite soaked in liquid media were used for both root induction and elongation phases.

Complete culture survival was obtained with $\mathbf{1 . 0}$ g $^{-1}$ PVP and the use of small shoot clusters as explants. BA at $2.0 \mathrm{mg} \mathrm{L}^{-1}$ gave the maximum mean shoot multiplication (2.7) from a single shoot at the $3^{\text {rd }}$ subculture; however, very short shoots were produced by shoot clusters after three further subcultures. BA at $1.0 \mathrm{~g} \mathrm{~L}^{-1}$ allowed a constant multiplication (about 2:1) of well-elongated shoots regardless of the explant type. The multiplication rates reported here are quite low, but comparable to data available in the literature for in vitro grown shoots of wild herbaceous $P$. lactiflora. The maximum rooting percentage $(50 \%)$ was obtained in liquid media, for shoots from $1.0 \mathrm{mg} \mathrm{L}^{-1}$ BA treated with $2.5 \mathrm{mg} \mathrm{L}^{-1}$ IBA, although not different from other IBA treatments ( 1 and $5 \mathrm{mg} \mathrm{L}^{-1}$ ). The present results are promising with regard to the in vitro phases. However, they also suggest further research in improving rooting and achieving successful acclimatization of healthy plants. If this goal is reached, micropropagation might represent an alternative vegetative propagation method for the reintroduction in the natural environment of this species, and its release at nursery level as plant for gardens.

Keywords

$\mathrm{BA}$, in vitro propagation, micropropagation, PVP, wild herbaceous peony

\section{Significance of this study}

What is already known on this subject?

- The present paper follows our previous results on wild $P$. officinalis embryo culture and shoot induction. Very poor data are available in the literature on micropropagation of this species.

What are the new findings?

- BA and PVP combinations strongly influenced shoot multiplication rates and survival. Best rooting of the shoots was in perlite soaked in liquid culture medium.

What is the expected impact on horticulture?

- Micropropagation might favour plant reintroduction in the natural environment and the use for gardening of wild P. officinalis, naturally propagated by rhizome or seeds.

\section{Introduction}

Herbaceous peony is propagated by rhizome or seeds under natural growing conditions. However, seeds need a couple of years to germinate, due to their complex dormancy (Tian et al., 2010). Paeonia officinalis L., subsp. officinalis, is a wild herbaceous peony growing on rocky slopes, up to 1,800 $m$ of altitude, from Southern France to Albany, that includes Tuscan and Emilian Apennines. At present, in Italy, these lands are mostly used for pasture and the reintroduction of wild animal species (roes, wild boars); this greatly counteracts the conservation and diffusion of $P$. officinalis (Botanical expert of Parco Nazionale Tosco-Emiliano 'Pania di Corfino', pers. commun.).

The in vitro culture of zygotic embryos of the Chinese herbaceous P. lactiflora Pall. on media enriched with gibberellic acid $\left(\mathrm{GA}_{3}\right)$ allowed to overcome their epicotyl dormancy, and to obtain healthy seedlings in a short time (Buchheim et al., 1994). Micropropagation was also attempted using different explant types, sugars, plant growth regulators (PGRs) and culture techniques (Hosoki et al., 1989; Gabryszewska, 1998, 2010; Gabryszewska and Kawa-Miszczack, 2009; Tian et al., 2010; Shen et al., 2012). However, many problems were reported to reduce micropropagation efficiency of this species, i.e., explant contamination, shoot browning and/or hyperhydricity (Hazarika, 2006), low percentages of in vitro rooting and poor/no plantlet survival after transfer ex vitro (Gabryszewska, 2010; Shen et al., 2012; Yu et al., 2012).

Poor data are available in the literature on in vitro propagation of $P$. officinalis. Bacterial and fungal contamination have been reported to affect cultures in the shoot induction and propagation stages; however, rooting showed the big- 
gest problems (Seyring, 2000, 2002). More recently, shoot cultures of $P$. officinalis, subsp. officinalis, were established using zygotic embryos as initial explants. Shoot production was induced from epicotyls on culture media enriched with 6-benzyladenine (BA), and was affected by cold storage treatments to embryos, cytokinin concentration and the genotype. Although the addition of polyvinylpyrrolidone $(0.5$ $\mathrm{g} \mathrm{L}^{-1}$ PVP 40,000) to the culture medium slightly reduced phenols phytotoxicity, most clones showed low proliferation, and did not survive after repeated shoot subcultures (Marino et al., 2014).

These findings suggested the present research aimed to develop a valid micropropagation protocol for P. officinalis, subsp. officinalis, with the final aim to reintroduce this species in the natural environment, and produce a new nursery product suitable for 'wild' gardens.

\section{Materials and methods}

\section{Plant material and growth conditions}

About two-year old shoot cultures of a wild P. officinalis, subsp. officinalis, clone (C3), that had been obtained through embryo culture (Marino et al., 2014), were used as donor plants for the present trials. They were grown on a maintenance medium (PMM) with the following composition: MS (Murashige and Skoog, 1962) salts at half strength, and (mg L ${ }^{-1}$ ): 100 myo-inositol, 1.0 thiamine hydrochloride, 0.5 nicotinic acid, 0.5 pyridoxine hydrochloride, 2.0 glycine, 0.5 BA, 0.25 indole-3-acetic acid (IAA), $0.2 \mathrm{GA}_{3}$, and ( $\left.\mathrm{g} \mathrm{L}^{-1}\right): 0.5$ PVP 40,000, 20 sucrose and 6.5 'Type A' (7178-01-A) bacteriologic agar. All the chemicals were from Sigma (Sigma-Aldrich, Milan, Italy), except for commercial sucrose and agar (Biokar, Diagnostic International Distribution, Milan, Italy). The medium was heated up to $90^{\circ} \mathrm{C}$ to obtain agar liquefaction, then the $\mathrm{pH}$ was adjusted to 5.6 before autoclaving at $121^{\circ} \mathrm{C}$ for $20 \mathrm{~min}$. Subcultures were performed at 30-35 d intervals, in $500-\mathrm{mL}$ glass jars ( $40 \mathrm{~mL}$ medium, 5 shoots). The jars were closed with twist-off screw metal caps, wrapped with polyvinyl chloride (PVC) transparent film for food (allowing gas exchange), and placed in a growth chamber under standard growth conditions (SGC): $23 \pm 1^{\circ} \mathrm{C}, 16$-h-light photoperiod at $30 \mu \mathrm{mol} \mathrm{m} \mathrm{m}^{-2} \mathrm{~s}^{-1}$ photosynthetic active radiation (PAR), supplied by Philips TLD 36 W/33 lamps).

\section{Shoot multiplication}

1. Experiment 1. Single shoots as explants. Well developed (10-15 mm long) shoots were randomly collected from donor cultures at the end of a maintenance subculture on PMM, transferred to 250-mL glass jars (with $30 \mathrm{~mL}$ medium and 2 shoots each, closed as reported above) on culture media with PMM basal composition, but enriched with variable BA (0.5, 1.0 and $\left.2.0 \mathrm{mg} \mathrm{L}^{-1}\right)$ and PVP (1.0, 2.0 and $\left.4.0 \mathrm{~g} \mathrm{~L}^{-1}\right)$ combinations. They were grown under SGC and processed for further two subcultures (Table 1a): at the end of each

TABLE 1. Treatments applied in the multiplication and rooting phases.

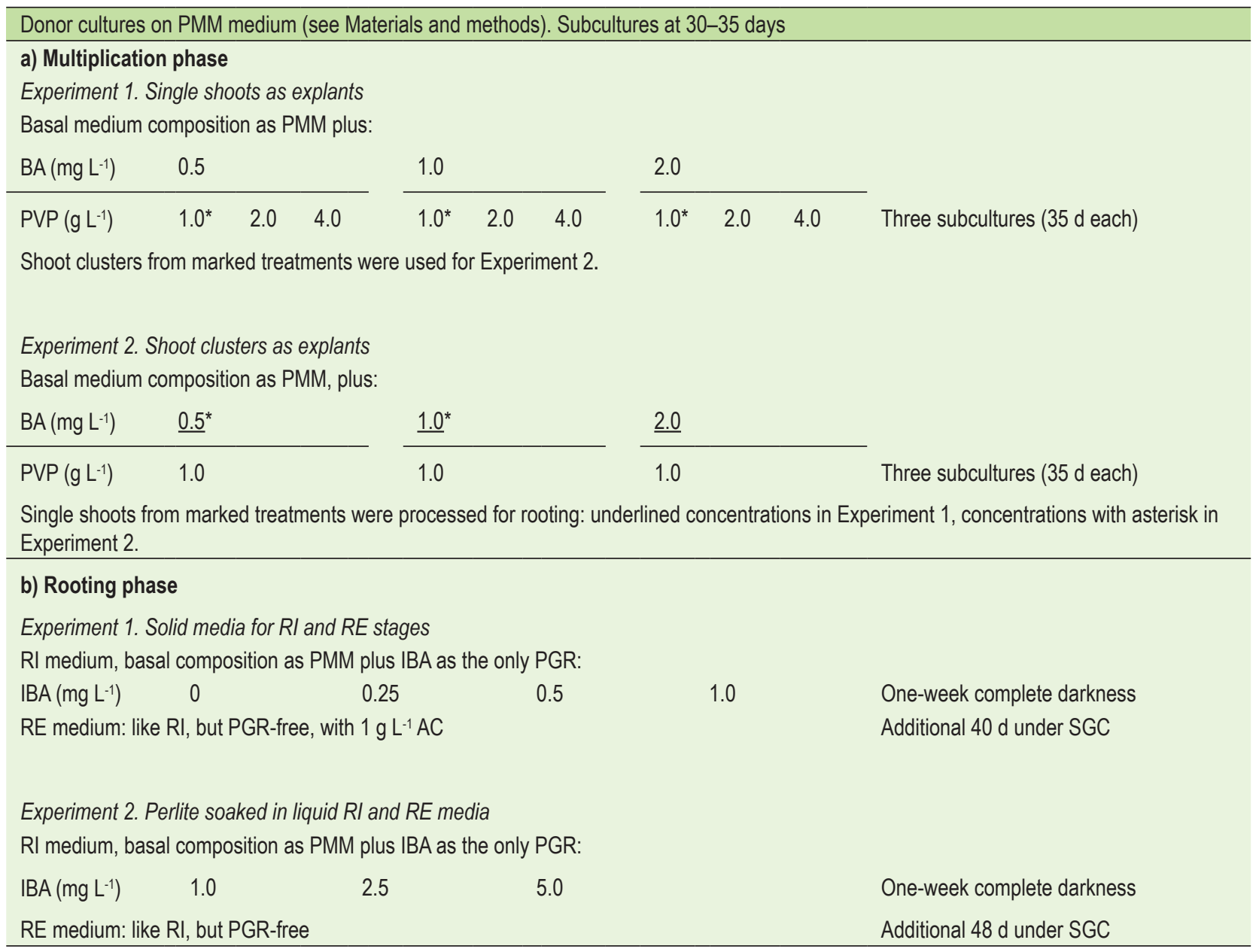

Abbreviations: AC, active charcoal; BA, 6-benzyladenine; IBA, indole-3-butyric acid; PGR, plant growth regulator; PMM, standard Paeonia multiplication medium; PVP, polyvinylpyrrolidone; RE, root elongation; RI, root induction; SGC, standard growth conditions. 
subculture, newly produced shoots (10-15 mm long) from each treatment were dissected and randomly transplanted to the same, fresh media. The number of dead shoots, the number of shoots ( $\geq 5 \mathrm{~mm}$ in length) produced from each single shoot (multiplication rate), and the length of the main shoot were checked at the end of each subculture (35 days) on four (first subculture) and five (second and third subcultures) jars (replications) per treatment.

2. Experiment 2. Shoot clusters as explants. Small shoot clusters (with 2 to 3 shoots each) were used as explants. They were randomly collected at the end of Experiment 1 , limited to the cultures grown on media with $1 \mathrm{~g} \mathrm{~L}^{-1} \mathrm{PVP}$, and processed for three further subcultures under the same culture conditions as reported above (Table 1a): the multishoots were divided into smaller clusters after each subculture, and these were used as explants in the subsequent subculture. Shoot multiplication rates were checked on five jars (replications), with two shoot clusters each, per BA concentration
(0.5, 1.0 and $\left.2.0 \mathrm{mg} \mathrm{L}^{-1}\right)$, at each subculture. Since shoot clusters were used as explants, the number of new shoots obtained from a single initial shoot was calculated at each subculture.

\section{Rooting}

1. Experiment 1. Following Seyring (2000) and Yu et al. (2012), a two-step rooting procedure was used. About 1520-mm long shoots from multiplication experiment 2 were transferred to root induction (RI) media in 250-mL glass jars (with $30 \mathrm{~mL}$ medium and 1 shoot each, closed as reported above). RI media had the same basal composition as PMM, but were enriched with variable concentrations $(0,0.25,0.5$ and $1.0 \mathrm{mg} \mathrm{L}^{-1}$ ) of indole-3-butyric acid (IBA), as the only PGR. Shoots were grown for one week in complete darkness at $24 \pm 1^{\circ} \mathrm{C}$, and transferred to a root elongation (RE) medium under SGC, for additional 40 days (Table 1b). RE medium had the same basal composition as RI, but was PGR-free and en-

TABLE 2. Shoot multiplication rates (the number of shoots obtained from one initial shoot) and number of dead shoots per jar (in brackets) of wild Paeonia officinalis subsp. officinalis shoots grown in three successive subcultures on proliferation media enriched with variable BA (0.5, 1.0 and $\left.2.0 \mathrm{mg} \mathrm{L}^{-1}\right)$ and PVP (1.0, 2.0 and $\left.4.0 \mathrm{~g} \mathrm{~L}^{-1}\right)$ concentrations (Experiment 1). See also Figure S2.

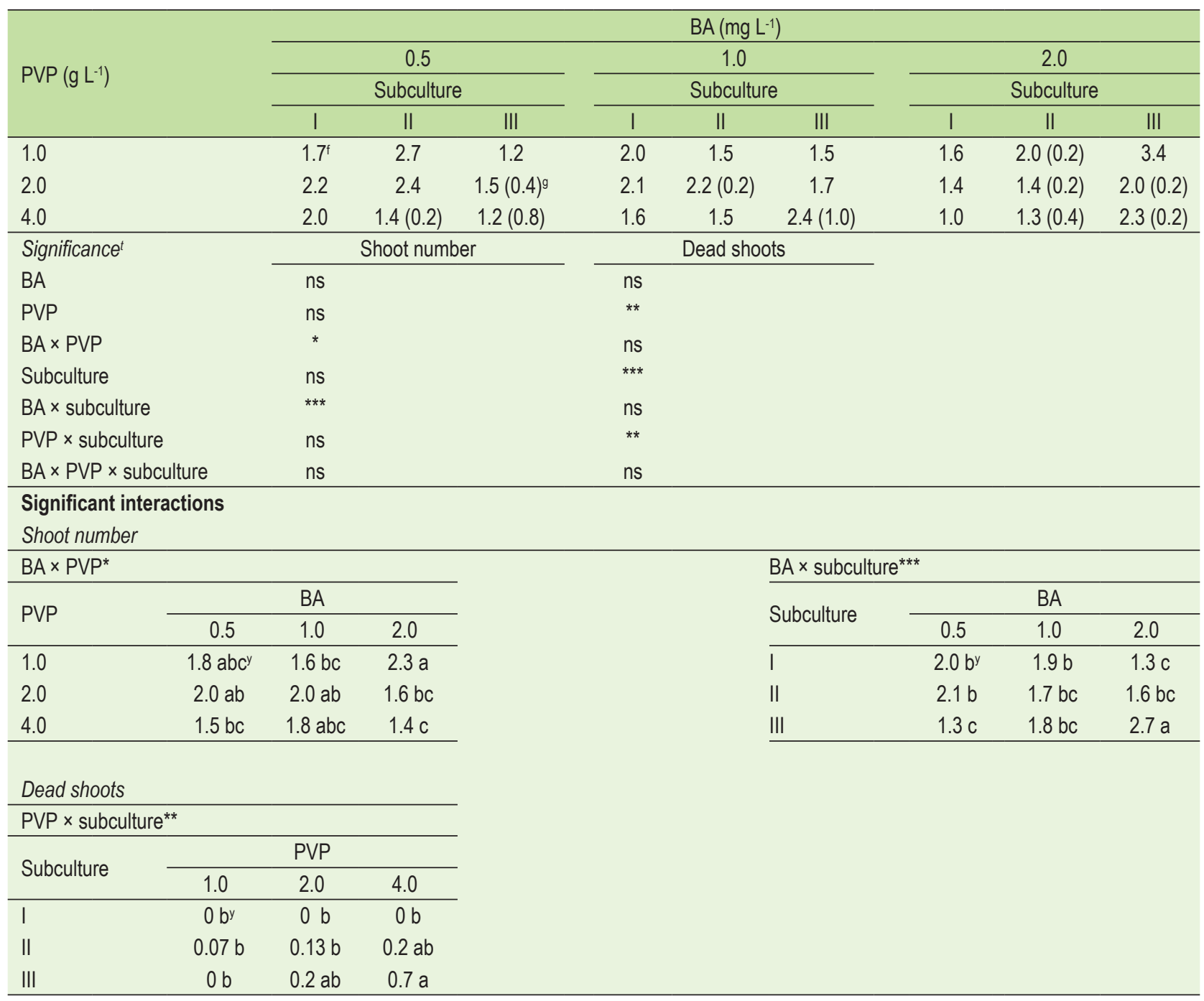

f Data on shoot multiplication rates refer to newly produced shoots $\geq 5 \mathrm{~mm}$ in length. Four ( 1 st subculture) and five jars $\left(2^{\text {nd }}\right.$ and $3^{\text {rd }}$ subculture) with two shoots each were used per culture medium and subculture.

If not reported, no shoot died.

${ }^{t}$ Significance: ns, ${ }^{*},{ }^{* *},{ }^{* * *}$, not significant, or significant at $P \leq 0.05, P \leq 0.01$ and $P \leq 0.001$, respectively.

${ }^{y}$ Means followed by different letters are statistically different at $P \leq 0.05$ (GLM, Tukey adjustment). 
riched with $1 \mathrm{~g} \mathrm{~L}^{-1}$ active charcoal (AC). The experiment was repeated one month later. Rooting frequencies, as well as root number and length were checked on a total of twenty shoots per each BA (in the multiplication medium) and IBA (in the RI medium) combination.

2. Experiment 2. The main difference with Experiment 1 was that shoots were grown in perlite (Agriperlite ${ }^{\circledR}$, Perlite Italiana, Trento, Italy) soaked in liquid medium (4 g perlite and $25 \mathrm{~mL}$ medium per each 250-mL glass jar: the lower part of perlite was under solution, the upper part was soaked by capillarity) in both root induction and root elongation phases (Figure S1). Moreover, it was limited to shoots from 0.5 and $1.0 \mathrm{mg} \mathrm{L}^{-1} \mathrm{BA}$; IBA was increased to $1.0,2.5$ and $5.0 \mathrm{mg} \mathrm{L}^{-1}$ in the RI media, and RE medium lacked AC (Table 1b). After one month in the RE phase, $10 \mathrm{~mL}$ PGR-free medium were added to each jar in order to counterbalance for medium evaporation. The experiment was repeated one month later. Rooting frequencies, as well as root number and length were checked after a total of $55 \mathrm{~d}$ (7 and $48 \mathrm{~d}$ on RI and RE media, respectively) in culture on a total of twelve shoots per treatment.

Acclimatization of rooted shoots was attempted in a sphagnum peat $\left(\mathrm{TKS}^{\circledR} 1\right.$ Floragard, Germany) and perlite mixture $(80 / 20 \mathrm{v} / \mathrm{v})$ in a growth chamber under SGC, but PAR increased to $70 \mu \mathrm{mol} \mathrm{m}^{-2} \mathrm{~s}^{-1}$.

\section{Statistical analysis}

The data on shoot multiplication rates, main shoot length, and root number and length were processed for the analysis of variance (ANOVA) in completely randomized factorial designs by SAS 9.0 (SAS Institute Inc., Cary NC, USA) General

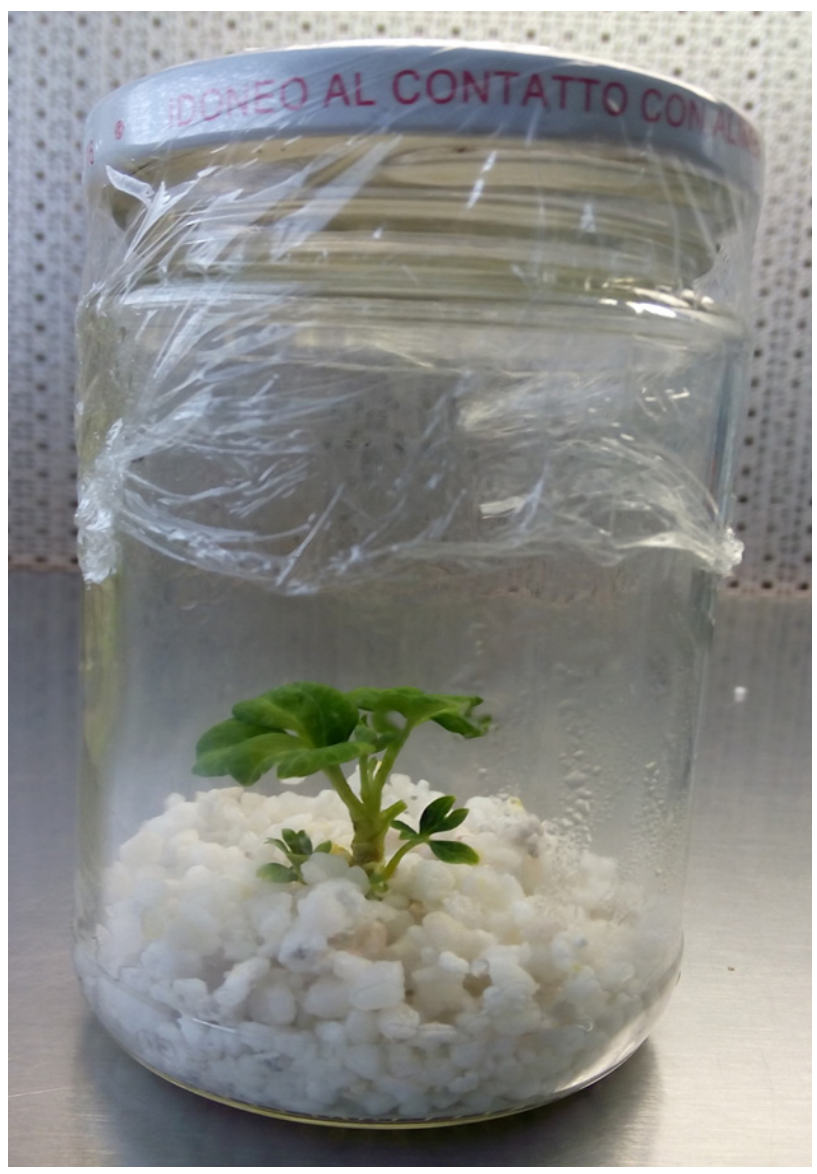

FIGURE S1. Paeonia officinalis, subsp. officinalis, shoot in the root elongation phase on perlite soaked in liquid medium.
Linear Model (GLM) procedure. The data were subjected to the homogeneity of variance before analysis. When ANOVA showed a statistical effect, mean separation was performed with Tukey adjustment, considering the factor interactions.

Due to stable behavior of donor cultures after repeated multiplication subcultures, the high variability in the rooting results and poor rooting, data of the two repetitions of each rooting experiment were combined together. Data on rooting frequencies were analyzed by the Log Linear Model analysis for multidimensional contingency tables (Zar, 1984), and are reported in tables as rooting percentages.

\section{Results}

\section{Shoot multiplication}

1. Experiment 1. Although not any single independent variable was significant, the 'BA $\times$ PVP' and 'BA $\times$ subculture' interactions were significant at $P \leq 0.05$ and $P \leq 0.001$, respectively. The mean shoot number produced from one initial shoot decreased with time in media with $0.5 \mathrm{mg} \mathrm{L}^{-1} \mathrm{BA}$ and, in contrast, increased with the highest BA concentration; instead, constant multiplication rates were found with $1 \mathrm{mg} \mathrm{L}^{-1}$ BA (Table 2). The maximum shoot multiplication (3.4) was obtained at the third subculture with $2 \mathrm{mg} \mathrm{L}^{-1} \mathrm{BA}$ plus $1 \mathrm{~g} \mathrm{~L}^{-1}$ PVP. On the other hand, in the presence of $1 \mathrm{~g} \mathrm{~L}^{-1} \mathrm{PVP}$, the mean shoot number with $2.0 \mathrm{mg} \mathrm{L}^{-1} \mathrm{BA}$ was significantly higher than $1.0 \mathrm{mg} \mathrm{L}^{-1} \mathrm{BA}$, and comparable to $0.5 \mathrm{mg} \mathrm{L}^{-1} \mathrm{BA}$

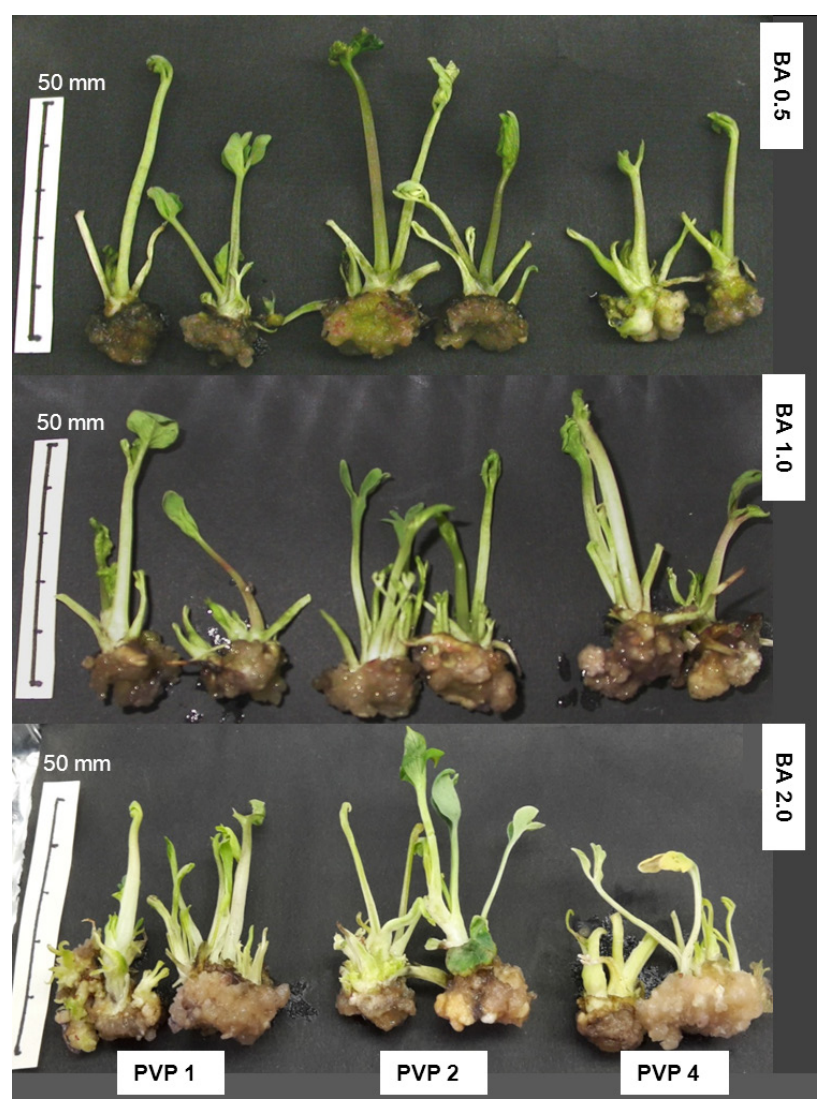

Figure S2. Paeonia officinalis, subsp. officinalis, shoots at the end of the third subculture on media enriched with variable BA (0.5, 1.0 and $2.0 \mathrm{mg} \mathrm{L}^{-1}$ ) and PVP (1.0, 2.0 and $4.0 \mathrm{~g} \mathrm{~L}^{-1}$ ) concentrations. Homogeneous, single shoots $(10-15 \mathrm{~mm}$ long) were used as initial explants at each subculture (multiplication Experiment 1). 
TABLE 3. Length (mm) of wild Paeonia officinalis subsp. officinalis main shoots in three successive subcultures on multiplication media enriched with variable BA $\left(0.5,1.0\right.$ and $\left.2.0 \mathrm{mg} \mathrm{L}^{-1}\right)$ and PVP (1.0, 2.0 and $\left.4.0 \mathrm{~g} \mathrm{~L}^{-1}\right)$ concentrations (Experiment 1).

\begin{tabular}{|c|c|c|c|c|c|c|c|c|c|}
\hline \multirow{4}{*}{$\operatorname{PVP}\left(\mathrm{g} \mathrm{L}^{-1}\right)$} & \multicolumn{9}{|c|}{$\mathrm{BA}\left(\mathrm{mg} \mathrm{L}^{-1}\right)$} \\
\hline & \multicolumn{3}{|c|}{0.5} & \multicolumn{3}{|c|}{1.0} & \multicolumn{3}{|c|}{2.0} \\
\hline & \multicolumn{3}{|c|}{ Subculture } & \multicolumn{3}{|c|}{ Subculture } & \multicolumn{3}{|c|}{ Subculture } \\
\hline & 1 & II & III & 1 & II & III & 1 & II & III \\
\hline 1.0 & $38.7^{f}$ & 42.6 & 47.6 & 37.6 & 44.3 & 51.4 & 42.8 & 28.0 & 25.6 \\
\hline 2.0 & 36.7 & 33.8 & 29.4 & 38.0 & 47.8 & 53.1 & 45.2 & 27.4 & 24.5 \\
\hline 4.0 & 26.9 & 44.2 & 49.1 & 38.7 & 43.5 & 36.6 & 44.4 & 33.7 & 20.3 \\
\hline
\end{tabular}

\begin{tabular}{lc}
\hline Significancet & $* * *$ \\
BA & $n s$ \\
PVP & $*$ \\
BA $\times$ PVP & ns \\
Subculture & $* * *$ \\
BA $\times$ subculture & ns \\
PVP $\times$ subculture & ns \\
BA $\times$ PVP $\times$ subculture &
\end{tabular}

Significant interactions

$B A \times P V P^{*}$

\begin{tabular}{|c|c|c|c|c|c|c|c|}
\hline & \\
\hline \multirow[b]{2}{*}{ PVP } & \multicolumn{3}{|c|}{$\mathrm{BA}$} & \multirow[b]{2}{*}{ Subculture } & \multicolumn{3}{|c|}{ BA } \\
\hline & 0.5 & 1.0 & 2.0 & & 0.5 & 1.0 & 2.0 \\
\hline 1.0 & $43.0 a^{y}$ & $44.9 \mathrm{a}$ & $32.4 \mathrm{~b}$ & 1 & $33.6 d^{y}$ & $38.1 \mathrm{bc}$ & $44.1 \mathrm{ab}$ \\
\hline 2.0 & $33.0 \mathrm{~b}$ & $46.8 \mathrm{a}$ & $32.9 \mathrm{~b}$ & II & $40.2 b c$ & $45.1 \mathrm{ab}$ & $29.2 \mathrm{~d}$ \\
\hline 4.0 & $39.7 a b$ & $40.3 \mathrm{ab}$ & $34.9 \mathrm{~b}$ & III & $41.4 \mathrm{ab}$ & $49.1 \mathrm{a}$ & $23.9 \mathrm{~d}$ \\
\hline
\end{tabular}

fData refer to four ( $1^{\text {st }}$ subculture) and five jars ( $2^{\text {nd }}$ and $3^{\text {rd }}$ subculture) with two shoots each per culture medium and subculture.

'Significance: ns, ${ }^{*},{ }^{* * *}$, not significant, or significant at $P \leq 0.05$ and $P \leq 0.001$, respectively.

y Means followed by different letters are statistically different at $P \leq 0.05$ (GLM, Tukey adjustment).

(BA $\times$ PVP, significant at $P \leq 0.05$. Table 2; Figure S2). Moreover, at the highest BA concentration, shoot multiplication rates were reduced with 2.0 and $4.0 \mathrm{~g} \mathrm{~L}^{-1} \mathrm{PVP}$. The number of dead shoots significantly increased with $4.0 \mathrm{~g} \mathrm{~L}^{-1} \mathrm{PVP}$ after repeated subcultures, regardless of BA concentration, and at a lesser extent (not significant) with $2.0 \mathrm{~g} \mathrm{~L}^{-1} \mathrm{PVP}$ (Table 2). Even a total of $40 \%$ and $50 \%$ shoots (respectively 0.8 and 1.0 shoot per jar) died at the third subculture with the highest PVP concentration, while no loss of cultures occurred with $1.0 \mathrm{~g} \mathrm{~L}^{-1} \mathrm{PVP}$ (the 'PVP $\times$ subculture' interaction was significant at $P \leq 0.01$ ).

The main shoot length increased with time with 0.5 mg L $\mathrm{L}^{-1} \mathrm{BA}$; while it was reduced to about one half from the first to the third subculture with the highest BA concentration (BA $\times$ subculture, significant at $P \leq 0.001$; Table 3 ).

2. Experiment 2. The shoot number at the third subculture (the sixth on the same culture medium) and the mean shoot number in the three successive subcultures were comparable to Experiment 1 (Table 4); however, newly produced shoots were very short in media with $2 \mathrm{mg} \mathrm{L}^{-1}$ BA (Figure 1). On the other hand, no explant died, regardless of medium composition.

\section{Rooting}

1. Experiment 1. Only IBA at $1 \mathrm{mg} \mathrm{L}^{-1}$ could induce root production. A maximum of $25 \%$ rooting was obtained in shoots from $0.5 \mathrm{mg} \mathrm{L}^{-1} \mathrm{BA}$; while no shoot from $2 \mathrm{mg} \mathrm{L}^{-1} \mathrm{BA}$ produced roots. Moreover, only one or two roots per shoot were produced (data are not reported in tables; Figure S3).

2. Experiment 2. A maximum of $50 \%$ rooted shoot was obtained with the $1.0 \mathrm{mg} \mathrm{L}^{-1} \mathrm{BA} / 2.5 \mathrm{mg} \mathrm{L}^{-1}$ IBA combination, although not statistically different from other treatments.
Root number also was not significantly affected by culture medium (Table 5). However, some shoot apex browning was found, in particular with the highest IBA concentration. Moreover the IBA effect on root length was unclear: best root elongation occurred with the $0.5 \mathrm{mg} \mathrm{L}^{-1} \mathrm{BA} / 5.0 \mathrm{mg} \mathrm{L}^{-1} \mathrm{IBA}$ combination, different from $0.5 \mathrm{mg} \mathrm{L}^{-1} \mathrm{BA} / 1.0 \mathrm{mg} \mathrm{L}^{-1}$ IBA and $1.0 \mathrm{mg} \mathrm{L}^{-1} \mathrm{BA} / 2.5 \mathrm{mg} \mathrm{L}^{-1}$ IBA treatments (Figure 2).

TABLE 4. Shoot multiplication rates (the number of shoots obtained from each initial shoot of the cluster) in wild Paeonia officinalis subsp. officinalis shoot clusters grown in three successive subcultures on proliferation media enriched with $1.0 \mathrm{~g} \mathrm{~L}^{-1}$ PVP and variable BA $\left(0.5,1.0\right.$ and $\left.2.0 \mathrm{mg} \mathrm{L}^{-1}\right)$ concentrations (Experiment 2).

\begin{tabular}{llcl}
\hline \multirow{2}{*}{ Subculture } & \multicolumn{3}{c}{$\mathrm{BA}\left(\mathrm{mg} \mathrm{L}^{-1}\right)$} \\
\cline { 2 - 4 } & 0.5 & 1.0 & 2.0 \\
\hline I & $1.5^{\mathrm{f}}$ & 1.7 & 2.0 \\
II & 1.4 & 2.1 & 1.9 \\
III & 1.4 & 1.8 & 2.7 \\
Mean & $1.4 \mathrm{~b}$ & $1.8 \mathrm{ab}$ & $2.2 \mathrm{a}$ \\
\hline Significance & & & \\
BA & $* *$ & & \\
Subculture & $\mathrm{ns}$ & & \\
BA $\times$ subculture & $\mathrm{ns}$ & & \\
\hline
\end{tabular}

fData on shoot multiplication rates refer to five jars, each with two shoot clusters as initial explants, per culture medium and subculture.

t Significance: ns, ${ }^{* *}$, not significant, or significant at $P \leq 0.01$. Means followed by different letters are statistically different at $P \leq 0.05$ (GLM, Tukey adjustment). 

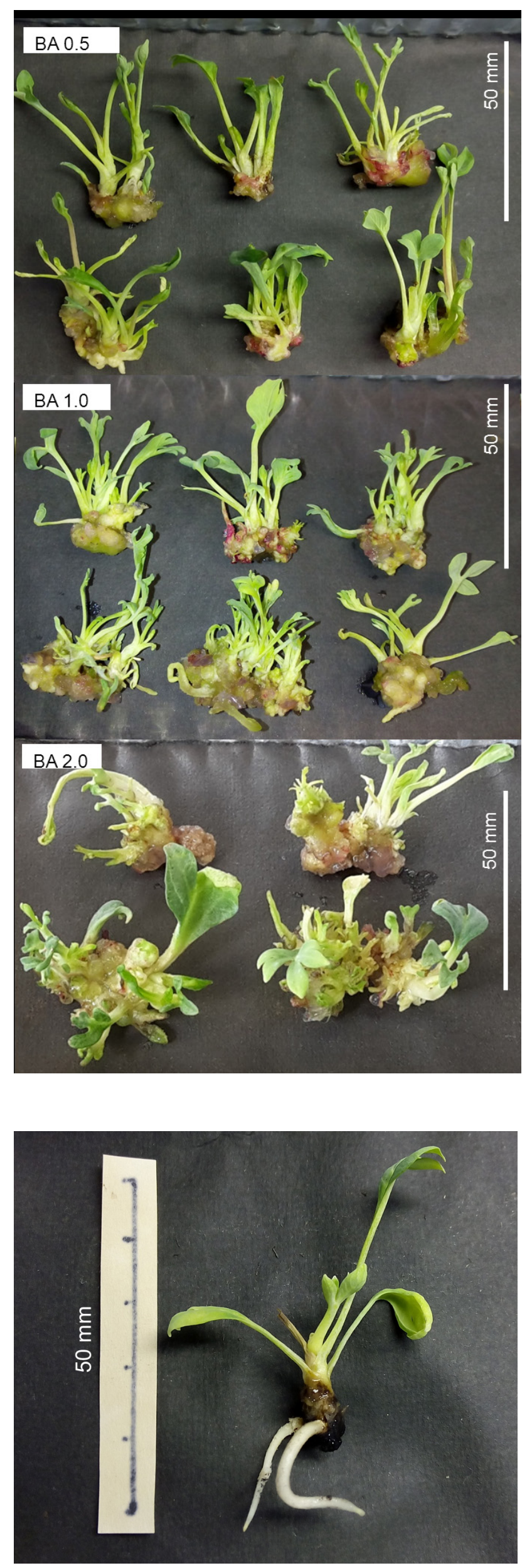

FigurE 1. Paeonia officinalis, subsp. officinalis, shoot clusters at the end of the third subculture (the sixth subculture on the same media) on media enriched with $1.0 \mathrm{~g} \mathrm{~L}^{-1} \mathrm{PVP}$ and variable $\mathrm{BA}\left(0.5,1.0\right.$ and $\left.2.0 \mathrm{mg} \mathrm{L}^{-1}\right)$ concentrations. At each subculture, the multishoots were divided into smaller shoot clusters ( 2 to 3 shoots) which were used as initial explants for the further subculture (multiplication Experiment 2).

FigurE S3. Rooted shoot of Paeonia officinalis, subsp. officinalis, from BA $0.5 \mathrm{mg} \mathrm{L}^{-1}$ and processed for a two-step rooting procedure (one week in complete darkness on a medium with $1.0 \mathrm{mg} \mathrm{L}^{-1} \mathrm{IBA}$, and transfer for additional $40 \mathrm{~d}$ on a PGR-free medium supplemented with $1.0 \mathrm{~g} \mathrm{~L}^{-1} \mathrm{AC}$ ), providing the use of agarized culture media in both the rooting phases. 

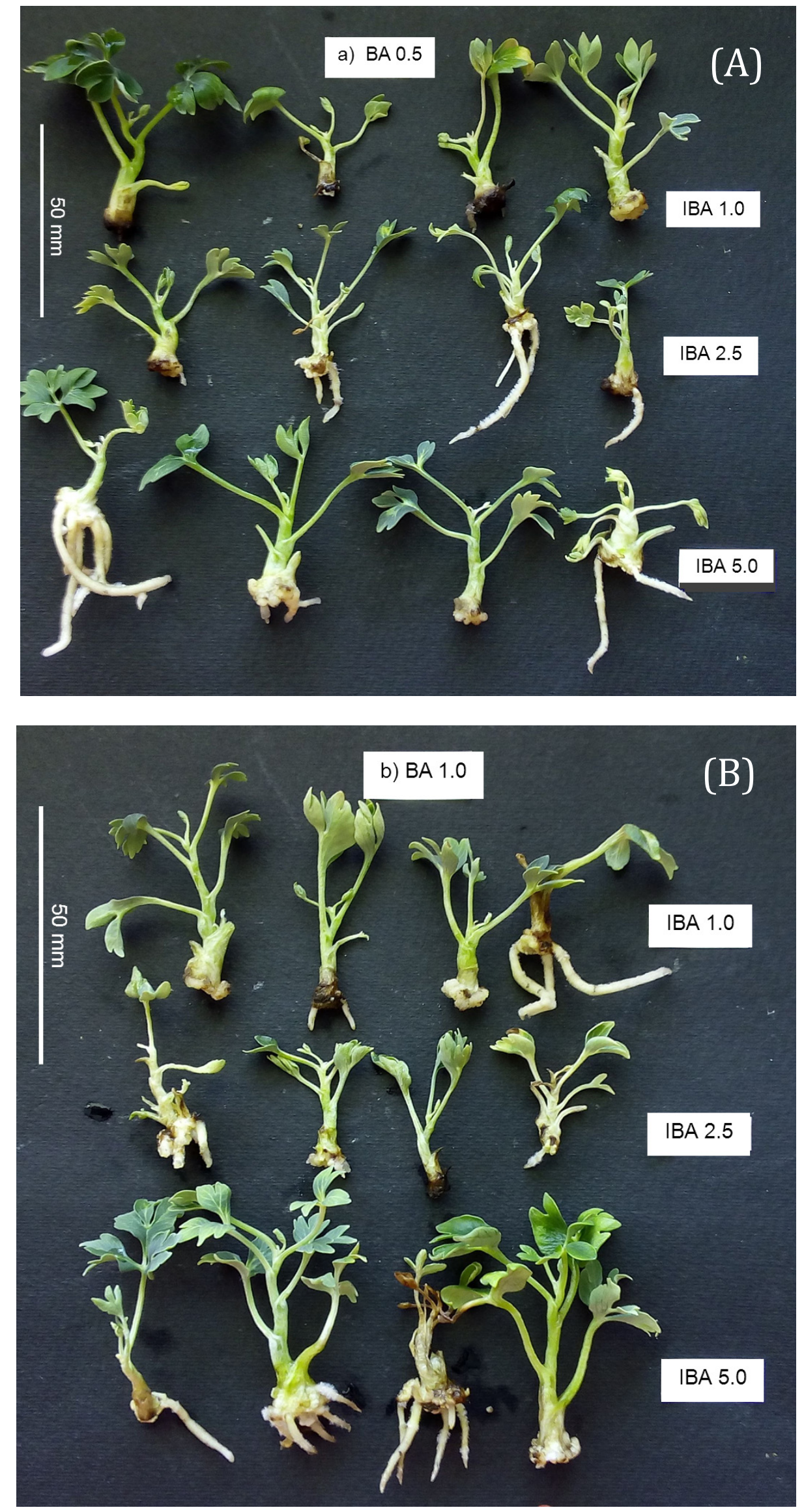

FIGURE 2. Rooting of Paeonia officinalis, subsp. officinalis, shoots, collected from agarized, PVP- $\left(1.0 \mathrm{~g} \mathrm{~L}^{-1}\right)$ and BA-enriched (0.5 and $1.0 \mathrm{mg} \mathrm{L}^{-1} \mathrm{BA}$ ) multiplication media (Figures 2a [top] and 2b [bottom], respectively), and processed for a two-step rooting procedure (one week in complete darkness on a RI medium with 1.0, 2.5 and $5.0 \mathrm{mg} \mathrm{L}^{-1}$ IBA, and transfer for additional $48 \mathrm{~d}$ on a PGR-free RE medium), providing the use of perlite soaked in liquid media in both the rooting phases (Experiment 2 ). 
TABLE 5. Rooting percentage, root number/rooted shoot, and root length of wild Paeonia officinalis subsp. officinalis shoots collected from cultures grown in agarized, BA-enriched media ( 0.5 and $\left.1.0 \mathrm{mg} \mathrm{L}^{-1} \mathrm{BA}\right)$, and transferred to perlite soaked in IBA-enriched (1.0, 2.5 and $\left.5.0 \mathrm{mg} \mathrm{L}^{-1}\right)$ liquid media and later in a PGR-free liquid medium.

\begin{tabular}{|c|c|c|c|c|c|c|}
\hline \multirow{3}{*}{$\mathrm{IBA}\left(\mathrm{mg} \mathrm{L}^{-1}\right)$} & \multicolumn{6}{|c|}{$\mathrm{BA}\left(\mathrm{mg} \mathrm{L}^{-1}\right)$ in the multiplication phase } \\
\hline & \multicolumn{3}{|c|}{0.5} & \multicolumn{3}{|c|}{1.0} \\
\hline & Rooting percentagef & Root numberf & Root length $(\mathrm{mm})^{f}$ & Rooting percentage & Root number & Root length $(\mathrm{mm})$ \\
\hline 1.0 & $25.0(3)^{g}$ & $1.5^{y}$ & $2.3 b^{y}$ & $16.7(2)$ & 2.5 & $17.6 \mathrm{a}$ \\
\hline 2.5 & $33.3(4)$ & 2.0 & $15.1 \mathrm{a}$ & $50.0(6)$ & 4.5 & $4.8 \mathrm{~b}$ \\
\hline 5.0 & $33.3(4)$ & 3.0 & $19.0 \mathrm{a}$ & $33.3(4)$ & 4.7 & $11.3 \mathrm{ab}$ \\
\hline Significance $^{t}$ & Rooting frequencies & Root number & Root length & & & \\
\hline $\mathrm{BA}$ & ns & ns & ns & & & \\
\hline IBA & ns & ns & ns & & & \\
\hline $\mathrm{BA} \times \mathrm{IBA}$ & ns & ns & ** & & & \\
\hline
\end{tabular}

${ }^{f}$ Data refer to 12 shoots per treatment, singly grown in $250-\mathrm{mL}$ glass jars.

${ }^{9}$ Rooting frequencies (in brackets) were analyzed by the Log Linear Model analysis.

tSignificance: ns, ${ }^{* *}$, not significant, or significant at $P \leq 0.01$, respectively.

y Means followed by different letters are statistically different at $P \leq 0.05$ (GLM, Tukey adjustment).

\section{Discussion}

Following previous results (Marino et al., 2014) on better effects of PVP than citric acid and AC in reducing tissue browning in P. officinalis, subsp. officinalis, PVP concentrations higher than that previously used $\left(0.5 \mathrm{~g} \mathrm{~L}^{-1}\right)$ were tested in the present research.

In many cases, it was impossible to distinguish axillary shoots from those derived from adventitious buds, mainly due to the formation of a white-green, compact callus at the explant base. Therefore, the number of newly produced shoots checked at each subculture included all of them $\geq 5 \mathrm{~mm}$ in length, which could be easily dissected.

In Experiment 1, the comparable mean multiplication rates obtained with $1 \mathrm{~g} \mathrm{~L}^{-1} \mathrm{PVP}$ in combination with 0.5 and $2 \mathrm{mg} \mathrm{L}^{-1} \mathrm{BA}$ might be tentatively explained by a delayed effect of PMM medium, in the first two subcultures, in shoots transferred to the reduced BA concentration, and/or to the presence of very small, uncountable shoot buds at the explant base, that elongated after a further subculture with the lowest cytokinin concentration. This effect should have been counteracted by the highest PVP concentration. This assumption is also supported by the fact that the main shoot length increased with time with $0.5 \mathrm{mg} \mathrm{L}^{-1} \mathrm{BA}$, and was strongly reduced at the third subculture with $2 \mathrm{mg} \mathrm{L}^{-1} \mathrm{BA}$. Afterward, as expected, shoot multiplication rate generally increased with $2 \mathrm{mg} \mathrm{L}^{-1} \mathrm{BA}$ and was reduced with $0.5 \mathrm{mg} \mathrm{L}^{-1} \mathrm{BA}$.

Tissue browning was reported to be controlled in P. lactiflora by PVP at $5 \mathrm{~g} \mathrm{~L}^{-1}$, regardless of the explant type (Rather and Paul, 2010). However, PVP concentrations of 2 and $4 \mathrm{~g} \mathrm{~L}^{-1}$ were detrimental to shoot proliferation, and/or increased the number of dead shoots in present Experiment 1; therefore, $1 \mathrm{~g} \mathrm{~L}^{-1}$ PVP was used in further trials. In Experiment 2, where shoot clusters were used as explants instead of single shoots, none of them died, probably due to a reduced damage during excision. It is well-known, in fact, that some plant species contain high concentrations of phenolic substances which undergo oxidation processes when cells are wounded or senescent; this leads to browning/blackening of in vitro cultured tissues, growth inhibition, and finally death of explants in many cases (George, 1993). On the other hand, since most shoots produced in Experiment 2 on media with $2 \mathrm{mg} \mathrm{L}^{-1} \mathrm{BA}$ were very short, it does not seem advisable to use so high BA concentration for up to six subcultures; in fact, the main shoot length was already reduced at the $2^{\text {nd }}$ and $3^{\text {rd }}$ subcultures, when single shoots were used as explants. Probably, the alternate use of media enriched with BA $2.0 \mathrm{mg} \mathrm{L}^{-1}$ and BA $0.5 \mathrm{mg} \mathrm{L}^{-1}$ might ensure good proliferation of well-elongated shoots. An additional shoot 'elongation phase' on media with reduced cytokinin concentrations is sometimes used in micropropagation, e.g., before rooting (George, 1993).

In previous trials, where epicotyls were used as initial explants, higher shoot multiplication rates than in present experiments were found in the first three subcultures after epicotyl explantation. However, the number of shoots produced per subculture strongly decreased during further subcultures, and most cultures died due to phenol release and accumulation near the shoot base (Marino et al., 2014). It is well-known that explants from zygotic embryos have high regenerative ability, which is gradually lost with progressive subculturing, depending also on the composition of the culture medium (Sahrawat and Chand, 2001; George et al., 2007). Moreover, present results agree with those reported for wild P. lactiflora species, grown on media enriched with $\mathrm{BA}$ and $\mathrm{GA}_{3}$, whose multiplication rates were much lower than in Chinese cultivars of commercial interest (Hosoki et al., 1989).

A two-step rooting procedure, as in the present research, was used for Paeonia officinalis, showing better rooting with IBA than NAA (Seyring, 2002). Due to the slow root production in both our rooting experiments, the culture period was prolonged (up to $55 \mathrm{~d}$ ) in comparison to the multiplication subcultures ( $35 \mathrm{~d})$, until the first appearance of some shoot apex browning. Instead, the highest rooting rates were recorded after 8-12 weeks in P. tenuifolia and P. officinalis 'J.C. Wegulin' (Seyring, 2000).

When agarized media were used (Experiment 1), low rooting was obtained, limited to shoots from $0.5 \mathrm{mg} \mathrm{L}^{-1} \mathrm{BA}$ treated with $1 \mathrm{mg} \mathrm{L}^{-1}$ IBA. The paper-bridge method on liquid culture enhanced rooting of $P$. lactiflora (Hosoki et al., 1989). These results suggested the use of liquid media, and higher auxin concentrations in Experiment 2, where only well-elongated shoots from 0.5 and $1.0 \mathrm{mg} \mathrm{L}^{-1} \mathrm{BA}$ were processed for rooting.

The use of perlite soaked in liquid media, and the increase of IBA in the RI phase improved rooting in terms of percentages and root number in respect to the previous experiment. 
This might be partially due to the dispersion in liquid medium of toxic metabolites, including phenols, which may instead accumulate near plant tissue on solid media (George, 1993). Moreover, porous materials other than paper, soaked in a liquid medium, were found to improve growth, ensuring better oxygen supply to tissues and roots than it would be in agarized medium or in static liquid (George, 1993).

An increase in IBA concentration was reported to produce a proportionate increase in the number of rooted shoots of Paeonia officinalis 'J.C. Wegulin' (Seyring, 2000). A similar trend was not found in our cultures, where no significant differences in rooting percentages and root number were found in a range of 1.0 to $5.0 \mathrm{mg} \mathrm{L}^{-1}$ IBA. This could make us think that these IBA concentrations are still suboptimal for P. officinalis subsp. officinalis. However, some shoot apex browning was found in present experiment with the highest IBA concentration. Good rooting results were obtained in $P$. suffruticosa after a root induction phase of 10 days on a medium supplemented with $15 \mathrm{mg} \mathrm{L}^{-1}$ IBA, although, following that period, auxin had a detrimental effect; moreover, rooting capacity was correlated to the endogenous levels of IAA and BA (Bouza et al., 1994). Different rooting results in P. tenuifolia and $P$. officinalis were supposed dependent on their different hormonal needs during root induction (Seyring, 2000). The type and concentration of sugar also influenced rooting of P. lactiflora (Gabryszewska, 2010). Therefore, further experiments seem advisable, where different IBA concentrations/ time of applications, and different sugars are tested, in order to improve rooting results.

No plantlet survived after transplant under ex vitro culture conditions, mainly due to fungi overgrowth. Very low rooting percentages (Shen et al., 2012; Yu et al., 2012) and poor or even no plantlet survival (Gabryszewska and Kawa-Miszczak, 2009; Gabryszewska, 2010; Shen et al., 2012) were also reported for P. lactiflora Chinese cultivars. The unsatisfactory acclimatization results were mainly ascribed to low root quality, unsuitable ex vitro culture conditions, ineffective transplant period, pathogen infections and bud dormancy of young plants.

In conclusion, present results are promising with respect to our previous trials. Constant multiplication rates (about 2 shoots explant ${ }^{-1}$ ) were obtained after repeated subcultures, without loss of plant material, when small shoot clusters were used as explants and grown on media added with $1 \mathrm{~g} \mathrm{~L}^{-1}$ PVP plus $1.0 \mathrm{mg} \mathrm{L}^{-1} \mathrm{BA}$. However, they also suggest further research, particularly in improving rooting results and achieving successful acclimatization of healthy plants; so that micropropagation might represent an alternative vegetative propagation method for wild $P$. officinalis, subsp. officinalis. If this goal is reached, micropropagation might facilitate the reintroduction of this species in the natural environment, and allow its possible use both as an ornamental herbaceous plant for gardens, and as a rootstock for the tree peony ( $P$. suffruticosa). At present, in fact, $P$. suffruticosa, which is less adapted than $P$. officinalis to poor and drought soils, is commonly used for this purpose (Rogers, 2009).

\section{Acknowledgments}

The research was supported by funds from the Italian Ministry of Education, University and Research (RFO funds) to Prof. Maria Eva Giorgioni. The authors wish to thank the Management of 'Parco Nazionale Tosco-Emiliano Pania di Corfino' and the 'Unione Comuni Garfagnana' for having supplied P. officinalis seeds.

\section{References}

Bouza, L., Jacques, M., Scotta, B., and Miginiac, E. (1994). Relation between auxin and cytokinin contents and in vitro rooting of three Peony (Paeonia suffruticosa Andr.). Plant Growth Reg. 15, 69-73. https://doi.org/10.1007/BF00024678.

Buchheim, J.A.T., Burkhart, L.F., and Meyer, M.M. (1994). Effect of exogenous gibberellic acid, abscisic acid, and benzylaminopurine on epicotyls dormancy of cultured herbaceous peony embryos. Plant Cell Tissue Org. Cult. 36, 35-43. https://doi.org/10.1007/ BF00048313.

George, E.F. (1993). Plant Propagation by Tissue Culture, Part 1, The Technology (Edington, Wilts.: Exegetics Ltd.).

George, E.F., Hall, M.A., and De Klerk, G.J. (2007). Plant Propagation by Tissue Culture, Vol. 1, The Background (Springer Science \& Business Media).

Gabryszewska, E. (1998). The influence of cytokinins, thidiazuron, paclobutrazol and red light on shoot proliferation of herbaceous peony cv. Jadwiga in vitro. J. Fruit Ornam. Plant Res. 6(3-4), 157-169.

Gabryszewska, E. (2010). The effects of glucose and growth regulators on the organogenesis of Paeonia lactiflora Pall. in vitro. J. Fruit Ornam. Plant Res. 18(2), 309-320.

Gabryszewska, E., and Kawa-Miszczak, L. (2009). Rooting in vitro and acclimatization in the greenhouse of herbaceous peony plantlets. $12^{\text {th }}$ National Conference In vitro Cultures, Poznan, Poland, 9-11 Sept. (poster).

Hazarika, B.N. (2006). Morpho-physiological disorders in in vitro culture of plants. Sci. Hortic. 108, 105-120. https://doi. org/10.1016/j.scienta.2006.01.038.

Hosoki, T., Ando, M., Kubara, T., Hamada, M., and Itami, M. (1989). In vitro propagation of herbaceous peony (Paeonia lactiflora Pall.) by a longitudinal shoot-split method. Plant Cell Rep. 8, 243-246. https:// doi.org/10.1007/BF00778543.

Marino, G., Grandi, F., Valente, C., and Giorgioni, M.E. (2014). Primi risultati sulla moltiplicazione in vitro di Paeonia officinalis a partire da embrioni (Preliminary results on in-vitro propagation of Paeonia officinalis through the use of embryos as initial explants). In Atti X Convegno sulla Biodiversità, Roma, 3-5 sept. (Roma: CNR). e-book, ISBN 978-88-97081-76-0, p.106-112.

Murashige, T., and Skoog, F. (1962). A revised medium for rapid growth and bioassays with tobacco tissue cultures. Physiol. Plant. 15, 473-497. https://doi.org/10.1111/j.1399-3054.1962.tb08052.x.

Rather, Z.A., and Paul, T.M. (2010). Studies on in vitro propagation of peony (Paeonia spp.) in Kashmir. http://dspaces.uok.edu.in/jspui// handle/1/1060.

Rogers, A. (2009). Peonies. (UK: Timber Press).

Sahrawat, A.K., and Chand, S. (2001). Continuous somatic embryogenesis and plant regeneration from hypocotyl segments of Psoralea corylifolia Linn., an endangered and medicinally important Fabaceae plant. Current Sci. 81(10), 1328-1331.

Seyring, M. (2000). Mikrovermehrung bei Paeonien. Ausfallrate ist noch zu hoch. Das TASPO Gartenbaumagazin 10(2), 30-31. (Braunschweig: Thalacker Medien).

Seyring, M. (2002). In vitro cloning of Helleborus niger. Plant Cell Rep. 20, 895-900. https://doi.org/10.1007/s00299-001-0420-1.

Shen, M., Wang, Q., Yu, X.N., and Teixeira da Silva, J.A. (2012). Micropropagation of herbaceous peony (Paeonia lactiflora Pall.). Sci. Hortic. 148, 30-38. https://doi.org/10.1016/j.scienta.2012.09.017.

Tian, D., Tilt, K.M., Dane, F., Woods, F.M., and Sibley, J.L. (2010). Comparison of shoot induction ability of different explants in herbaceous peony (Paeonia lactiflora Pall.). Sci. Hortic. 123, 385389. https://doi.org/10.1016/j.scienta.2009.10.007. 
Yu, X.N., Wu, H.J., Teixeira da Silva, J.A., and Shen, M.M. (2012). Multiple shoot induction and rooting of Paeonia lactiflora 'Da Fu Gui'. African J. Biotech. 11(41), 9776-9781.

Zar, J.H. (1984). Biostatistical Analysis (Englewood Cliffs, NJ: Prentice-Hall Inc.).

Received: Sep. 19, 2017

Accepted: Mar. 6, 2018

Addresses of authors:

G. Marino, F. Grandi, E. Muzzi and M.E. Giorgioni*

Dip. Scienze e Tecnologie Agro-Alimentari (DISTAL),

Università di Bologna, Viale Fanin 44, 40127 Bologna, Italy

* Corresponding author;

E-mail: mariaeva.giorgioni@unibo.it

Tel.: +39051 20964059; Fax: +390512096401 